\title{
Un modelo electoral de mayor equidad y mejor representación
}

\author{
Manlio Fabio BeLtRones*
}

* Presidente de la Junta de Coordinación Política del Senado de la República. 
Los criterios constitucionales de equidad en la competencia electoral y de mejor calidad en la representación política son los que en buena mediada guiaron el diseño y aprobación de la reforma electoral de 2007, y los mismos que podrán garantizar la correcta marcha de los comicios generales de 2012 y la legitimidad de quien resulte electo presidente, así como de los representantes populares federales y autoridades locales.

Aunque la elección intermedia de 2009 fue la primera prueba de viabilidad y consistencia del nuevo modelo electoral bajo los estatutos de esta reforma, y en todos los casos los candidatos electos pudieron asumir sus cargos respectivos en los términos constitucionales previstos, no cabe duda de que, por su dimensión nacional, la elección de 2012 plantea un reto mayor que requiere la revisión del contexto en que tendrá lugar esta competencia, igual que los elementos generales de la nueva normatividad electoral, su pertinencia en las condiciones políticas y sociales que son previsibles a lo largo de todo el proceso electoral y los pendientes que desde ahora podemos avizorar en materia de legislación electoral y también en relación al régimen de gobierno.

La reforma electoral de 2007 fue la de mayor alcance desde 1996, pues con ella se garantizó que el financiamiento público de los partidos prevaleciera sobre el privado, se estableció el Tribunal Electoral, adscrito al Poder Judicial de la Federación, para la calificación de las elecciones federales y se definió al IFE como una institución autónoma del Estado, entre otras reformas que fueron cruciales para que ocurriera la primera alternancia en el poder a nivel federal en el año 2000. Es ampliamente conocido que las lagunas jurídicas en la normatividad, la polarización política y el dominio de los medios de comunicación en la elección de 2006, evidenciaron la necesidad inaplazable de una nueva reforma electoral como la aprobada en 2007.

Cabe recordar en el ambiente de encono y controversia jurídica que siguió a la elección de julio de 2006, la reforma electoral fue el primer resultado del proceso de reconciliación y construcción de acuerdos que estableció la Ley para la Reforma del Estado, promulgada en abril de 2007. Esta referencia es fundamental porque fue en el marco del trabajo legislativo sobre reformas como la de seguridad y justicia penal, y con la expectativa de una reforma del régimen de gobierno, aún inconclusa, fue posible formar los consensos que dieron lugar a la reforma electoral. 
Dicho en otras palabras, la experiencia reciente sugiere la dificultad de avanzar en la actualización continua de la normatividad electoral cuando este esfuerzo no se acompaña de reformas y acuerdos paralelos en torno al régimen político. En términos conceptuales, podría decirse que el desarrollo de los mecanismos y normas de la democracia procedimental y representativa tiene un horizonte limitado cuando concurren en el mismo esquema de gobierno y no se modifica el diseño institucional del régimen político.

Cuando se trata de cambios de gran calado en la legislación electoral, para que éstos tengan éxito deben ir de la mano con la reforma institucional. También es cierto que cualquier intento de retornar a normas electorales que no corresponden al desarrollo de la pluralidad política, pone en riesgo el avance histórico logrado en más de tres décadas de reformas electorales en los rubros de equidad, legalidad, imparcialidad y representación.

Hay que tener presente entonces, que la evolución de la normatividad electoral es un resultado fundamental de la transición de un régimen de partido casi único a un sistema plural y competitivo, lo cual se refleja en los múltiples contrapesos y equilibrios institucionales que ahora encontramos en el régimen político. Así se entiende, por ejemplo, la función activa que ha desarrollado el Senado de la República desde la LXI Legislatura que empezó a laborar en diciembre de 2006; en ella sobresale el impulso de un ciclo de reformas institucionales sustentado en el consenso de una amplia pluralidad de fuerzas parlamentarias.

Una referencia adicional en este breve recuento del entorno que caracteriza la puesta en práctica del nuevo modelo electoral en la elección general de 2012, es el reto que para todas las fuerzas políticas representa el bajo nivel de reconocimiento cívico que tienen los partidos políticos (20\%) y cuya expresión más conspicua, además del abstencionismo, fue el llamado al voto nulo que se manifestó en la elección intermedia de 2009, el cual llegó a significar cerca del 10\% del voto emitido en algunas regiones.

Tiene gran relevancia reflexionar en qué medida será capaz la nueva normatividad electoral de representar y canalizar la expresión política de las nuevas generaciones, en particular las que no han obtenido oportunidades de empleo formal y educación de calidad, y hasta qué punto tendrá el nuevo modelo electoral la virtud de traducir la diversidad y pluralidad del mosaico político nacional en una representa- 
ción cualitativa que sustente la legitimidad del nuevo gobierno y su mandato frente a la complejidad de los retos económicos, sociales y de seguridad que tiene el país.

Los asuntos anteriores conducen a revisar algunos contenidos de la reforma electoral de 2007, en particular los aspectos que buscan contrarrestar una elección mediática que reste equidad a la competencia y disminuya la calidad de la representación política.

La reforma de 2007 representó un punto de inflexión en la transferencia de recursos públicos a los medios de comunicación electrónicos, ya que se prohibió la compra directa de espacios en radio y televisión y se estableció la autoridad del Instituto Federal Electoral (IFE) en la administración de los tiempos de que dispone el Estado para los partidos políticos.

Así fue revertida la tendencia observada en los comicios de 2000 y 2003, cuando cerca de la mitad del financiamiento público destinado a los partidos fue a parar a manos de los consorcios de la comunicación privada, y se avanzó en la instrumentación del modelo de financiamiento que privilegia las prerrogativas públicas y reduce las fuentes privadas.

Esto no sólo ha servido para refrendar el poder de elección de los ciudadanos al asegurar que los medios de comunicación sean, efectivamente, un instrumento de la democracia electoral y no un factor determinante de su resultado: también se ha restituido equidad a la competencia electoral al garantizar que el acceso al financiamiento privado, o la compra de espacios en los medios electrónicos por parte de terceros, no incline la balanza en las preferencias electorales.

Estos aspectos de la nueva normatividad electoral han generado una intensa controversia pública y legal desde su adopción. Algunos han argumentado la violación de sus libertades civiles, y, por otro lado, han surgido señalamientos de que en una sociedad de desigualdades extremas, la disposición de recursos privados no debe ser la fuente que determine el acceso al poder político y limite las posibilidades de quienes carecen de medios pecuniarios para tener suficiente presencia en los medios de comunicación.

Este principio de equidad en el acceso a los medios de comunicación y limitación al financiamiento privado, fue debidamente acompañado por una fiscalización mayor de los partidos y sus (pre)campañas, cuando se creó un órgano de fiscalización del IFE que consolida la rendición de cuentas sobre el uso que hacen los partidos de los recursos públicos y cancela el recurso al secreto bancario, fiduciario y fiscal. 
Al mismo tiempo, la mayor fiscalización de los partidos políticos por parte de la autoridad electoral contribuirá a restituir el prestigio y la confianza en los partidos como entidades de interés público y al servicio de los intereses ciudadanos.

Tanto la disminución del gasto en las campañas electorales como la nueva fórmula de financiamiento público de los partidos, que implica recortar casi la mitad en el caso de la elección presidencial, así como reducir los tiempos de campaña y regular las precampañas, habrán de redundar en que se aprecien mejor las funciones de representación y canalización de demandas por parte de los partidos, e inclusive en la percepción positiva de la democracia como forma de gobierno.

El hecho de reducir la duración de las campañas presidenciales de 186 a 90 días, es un ejemplo del impacto que tendrá la nueva normatividad que va a regir el proceso electoral de 2012 en la vida cotidiana y en las percepciones públicas.

La equidad de la competencia electoral y la calidad de la representación están garantizadas en la nueva legislación electoral con más facultades y atribuciones para las autoridades electorales: el IFE y el Tribunal Electoral del Poder Judicial de la Federación (TEPJF). El primero se fortalece con la creación de una contraloría general y una renovación escalonada del Consejo General del IFE y de los magistrados de la Sala Superior del TEPJF que, de manera permanente, permitirá combinar experiencia y novedad, al tiempo que se establecen procedimientos y reglamentos que permitirán aplicar sanciones inmediatas que no impidan el desarrollo de las distintas etapas del proceso electoral ni la resolución de las controversias que se susciten eventualmente.

Con lo anterior, parece factible que el nuevo modelo electoral garantice transparencia e imparcialidad de los comicios y el desarrollo de condiciones equitativas de competencia política, lo que propiciará la participación de las nuevas generaciones de electores y una mejor representación de la pluralidad política del país. Esto será posible, además, por dos elementos adicionales que me interesa subrayar.

Por un lado está el compromiso que establece la regulación electoral para que el IFE administre las modalidades de un par de debates entre los candidatos presidenciales - que tendrán lugar en los meses de mayo y junio- que van a ayudar a compensar el volumen y la brevedad de los spots con discusiones de fondo sobre las propuestas electorales y de gobierno de los distintos partidos. 
Cabe insistir en la relevancia de estos debates porque la equidad y la calidad de la representación deben desembocar en la elección de los candidatos con las mejores propuestas para poner orden y dar rumbo a la nación.

Si bien es cierto que los estudios electorales contemporáneos resaltan la relevancia de los candidatos por encima de los programas, también lo es que un candidato sin programa o experiencia para instrumentar su programa resulta ser una opción limitada, sobre todo en las circunstancias actuales del país, en las que se espera claramente que el fin último de la normatividad y los procesos electorales sea el cambio de las condiciones de vida y las perspectivas de bienestar de la población.

Otro aspecto novedoso de la elección general de 2012 consistirá en la consolidación de las funciones de fiscalización y observación electoral que desempeñan desde hace tiempo las organizaciones civiles de origen nacional e internacional. Sin duda, los instrumentos de transparencia y rendición de cuentas que establece la nueva normatividad electoral, así como los nuevos dispositivos de las tecnologías de la información y comunicación, habrán de servir como insumos fundamentales para la supervisión ciudadana de las distintas etapas y eslabones del proceso electoral, así como para el escrutinio y la denuncia de las posibles prácticas ilegales en que puedan incurrir los candidatos, partidos o entidades ajenas a la competencia política.

No omito señalar el amplio número de cabos sueltos detectados después de la elección intermedia de 2009 en la nueva normatividad electoral, los cuales, lamentablemente, no han sido subsanados en los tiempos establecidos por la ley para que, en caso de ser aprobados, pudieran tener vigencia en el proceso electoral de 2012.

Me refiero a temas relevantes como la ley secundaria que debe regular el derecho de réplica, la falta de desarrollo de las causas de nulidad de una elección, la actualización de la tipología de delitos electorales, las normas que reglamentan la prohibición constitucional sobre el uso de recursos públicos en los procesos electorales, la reducción en la cantidad de spots, la homologación de la ley de radio y televisión con las nuevas disposiciones del Cofipe, así como la controversia que genera la falta de acuerdo para el nombramiento de tres consejeros electorales.

Sin ánimo de subestimar el alcance de estos pendientes en la legislación electoral y la posibilidad de subsanarlos en periodos legislati- 
vos subsecuentes - para su vigencia en procesos electorales futuroscreo que debe tenerse en cuenta que el hecho de que no haya sido aún posible completar el proceso legislativo correspondiente a la reforma política ya aprobada en el Senado de la República, ha sido un factor que reduce la posibilidad de un acuerdo oportuno en torno a los pendientes normativos de la legislación electoral.

Ambos procesos, la reforma política y la actualización de la regulación electoral, van de la mano porque aspectos concretos como las candidaturas independientes, la iniciativa ciudadana y la reelección de legisladores habrán de contribuir a elevar la calidad de la representación política de los ciudadanos, incentivar la transparencia en la vida interna de los partidos y mejorar la calidad de los procesos legislativos.

En conjunto, estas reformas habrán de servir para elevar el reconocimiento ciudadano de la calidad y utilidad de nuestra democracia, los partidos políticos y los procesos electorales, ya que estamos convencidos de que el fin último de la competencia y la organización políticas es servir a la población, ofrecer instrumentos de cambio y reforma institucional y en la hora actual, ayudar a recuperar la seguridad pública y proveer empleo y bienestar social para las familias. 